\title{
The perspective of ventricular noncompaction as seen by a nonagenarian
}

Paul R. Lurie

\author{
Department of Pediatrics, Albany Medical College, Albany, New York, United States of America
}

\begin{abstract}
The persistence of so-called spongy myocardium was first reported in humans in the 1960s. Subsequently, a few reports described the condition, utilizing inconsistent facts and terminology. In 1990 the first report appeared using the term "noncompaction", and detailed its clinical implications. Following this report, more descriptions of patients with noncompaction entered the literature. Prior to the availability of high resolution crosssectional echocardiography, most cases of noncompacted myocardium escaped detection, as few patients underwent angiography. In this essay, I seek to adjudicate and clarify several confusions and controversies in the current literature including the acquired nature of hypertrabeculation, the fate of the so-called sinusoids, the relationship to coronary arteries, and noncompaction as another congenital malformation. The embryonic timing of cessation and reinitiation of compaction is conjectured as an explanation of the varied configurations of noncompaction as seen as a clinical entity. The clinical outcomes of decreased contractility, arrhythmia, and thromboembolism, have been stressed in the current literature, but more study is needed of the gray area between the normal variant and minimal noncompaction. A plea is made for the standardization of methods and terminology.
\end{abstract}

Keywords: Myocardium; embryology; paediatrics; cardiac failure

$\mathrm{V}$

ENTRICULAR NONCOMPACTION FIRST ENTERED the medical literature in 1990, after which ensued an explosion of interest in a previously neglected subject (Fig. 1). The morphologic basis of ventricular noncompaction can be defined simply as a portion of the ventricular myocardium ceasing to mature beyond its embryonic spongy state. Clinically, this may be coupled with loss of contractility, arrhythmia, and thromboembolism.

I began my career in paediatric cardiology in 1948, as the specialty blossomed in the era following the Second World War. Important developments, both diagnostic and therapeutic, appeared almost daily as we plucked the low-hanging fruit. In this essay, I seek to understand how a subject that attracts such interest today was completely missed by us voracious members of that generation. I will comment on some aspects of

Correspondence to: Paul R. Lurie, MD, 334 State Street, Albany, NY 12210, USA. Tel: +518 436 0903; E-mail: PLURIE@nycap.rr.com

Accepted for publication 20 December 2007 the subject that have been both confused or neglected. I do not consider it to be a review. There are several excellent offerings fulfilling that criterion. ${ }^{1-3}$ I have no expertise in pathology, embryology, echocardiography, or more advanced imaging technology. I am a long retired paediatric cardiologist, with much time to think about the observations of others. I have read many papers, and troubled many colleagues with telephone calls, e-mails, and letters, seeking their opinions and profiting from their experience.

\section{Memoir}

"The hearts of primitive vertebrates, such as the hagfish, are formed of interlacing muscle fibers bathed in the same pool of blood that they pump. In the early embryonic life of the higher vertebrates, a similar condition exists, in which the heart wall is a loose meshwork of developing myocardial fibers. Relatively large spaces between the muscle trabeculations contain blood which circulates back and forth from the cavities with the heart beat. With gradual condensation of the 


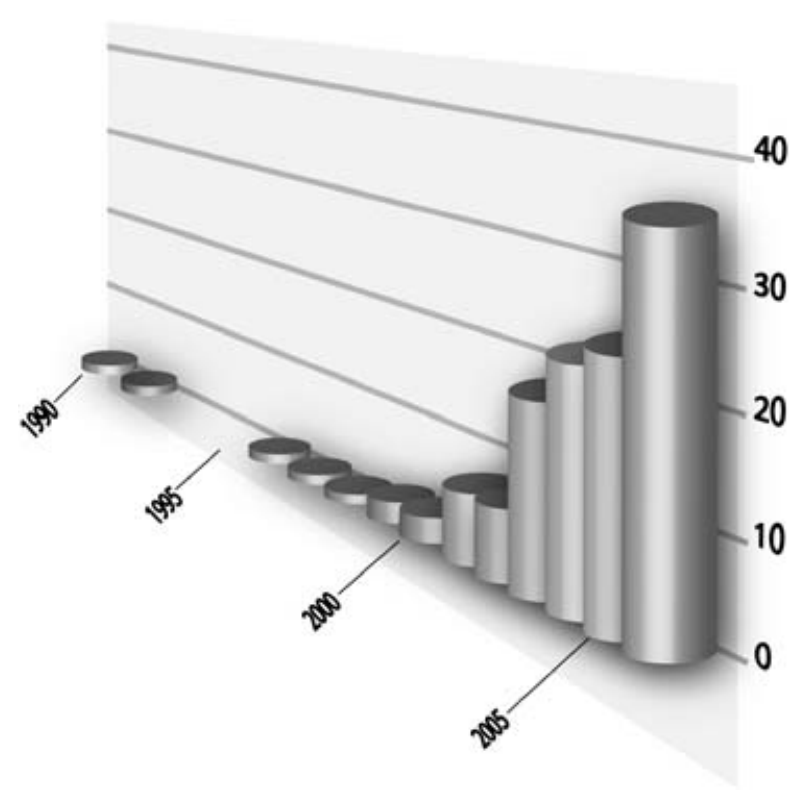

Figure 1.

The graph shows the interest in noncompaction, or non-compaction, as judged by citations each year subsequent to the initial use of the term in 1990. The data is sourced from OVID, with irrelevant items removed.

myocardium, most of these spaces become flattened sinusoids, while some remain as deep clefts continuous with the ventricular cavities."

In the early 1960s, my colleagues and I at Indiana University developed an interest in coronary arterial anomalies. ${ }^{5}$ I wrote a chapter on the subject for a new textbook then. The above epigraph is the first paragraph of that chapter. That work alerted me to the possibility that so-called "primitive" myocardium might result from an arrest in myocardial development, and I began to watch contrast ventriculograms for such a finding. Many years later, in 1978, I saw a full-blown example of arrested myocardial development. As I performed a left ventricular contrast injection in a 4-month old infant with cardiomyopathy, congestive failure, and multifocal arrhythmias, the most amazing picture appeared on the screen. I replayed the developed film a hundred times, and the images remain imprinted in my memory 30 years later. I was reminded of a squash ball, a compact spherical left ventricle, barely moving in systole, with most of the force of contraction coming from an active septum. And most amazing of all, the walls of the ventricle were thick and spongy, so thick as almost to occlude the ventricular cavity, with contrast flowing freely through the sponge and penetrating to the epicardium. I should have reported this finding, but deferred in hopes of learning more. The case file remained in a folder marked "spongy myocardium", and was shredded when I retired, along with other projects that never reached fruition. Now I cannot even recall the name of the patient! Recently, with the help of colleagues at Childrens' Hospital of Los Angeles, we attempted to resuscitate the data on this patient but, without a name, the attempt failed. The only trace left is the fragmented tabular data on Case \#16, with "failure of myocardial development, spongy myocardium" in a monograph on endomyocardial biopsy. ${ }^{6}$ The histologic, and electron microscopic, findings showed no unusual or specific findings. That experience sensitized me to this subject, and motivated me to compose this work.

\section{What's in a name?}

The earliest relevant publication that I found, dating from 1967,', termed the phenomenon "Persistenz myokardialer Venensinusoide." This description was based on a single contrast ventriculogram, showing deep clefts penetrating almost to the epicardium, without filling of the coronary arterial system, in a heart otherwise not malformed except for a mildly hypoplastic aorta. Other publications prior to 1990 used confusing terminology and facts. ${ }^{8,9}$ The most noteworthy confusion was with the myocardial appearance of pulmonary valvar atresia in the setting of an intact ventricular septum, with major fistulous communications, often inappropriately termed sinusoids, extending between the right ventricular lumen and the coronary arteries, and decompressing a blind ventricle. There is the possibility that the embryologic fault involved in isolated compaction can coexist in some of these cases, but to my knowledge no one has made that point. Before 1990, there were a few additional reports in English using other terms, such as hypertrabeculation, dysplasia, spongy, spongiosum, noncondensation, and honeycombing.

The condition of arrested myocardial development had no consistent nomenclature until 1990, when a group at University of California Los Angeles published a study of 8 cases with this particular ventricular configuration. ${ }^{10}$ They were the first to use the term "ventricular noncompaction." They included the descriptor "isolated" because the condition was unassociated with other congenital malformations. In this concise landmark paper, the authors recognized an important feature beyond impaired contractility and arrhythmias that I had not seen - an association with embolic phenomenons. The group from Los Angeles also noted a familial occurrence in some and, in others, dysmorphic facial features, both suggesting a genetic cause. The authors reported necropsy confirmation of the cardiac findings in 3 of the patients.

With their study, Chin et al. ${ }^{10}$ unleashed enthusiastic recognition of this phenomenon that had always been there. Thus, I consider it a noteworthy piece 
of medical history. This is my explanation for what happened. Firstly, "noncompaction" was catchy. "Spongy" could have applied to the brain or other organs, and "nonconsolidation," "noncondensation," and "hypertrabeculation" all had too many syllables. "Noncompaction" was a hit! Secondly, their paper coincided with a burgeoning of both noninvasive imaging techniques and research into genetics.

I have spoken with the authors of the article that opened the noncompaction floodgates by telephone, e-mail, and correspondence, and can relate the events leading to the birth of the name. First, the setting was a clinicopathologic conference at University of California Los Angeles, which staff periodically conducted as a "brainstorming session." Next, the actors. Thomas Chin, the lead author, was then a fellow in paediatric cardiology. He now heads his own division at the University of Tennessee. Joseph Perloff, known for anticipating important developments and pioneering director of an early clinic for adults with congenital cardiac disease, saw the importance of publishing the findings. Roberta Williams, the head of the division of paediatric cardiology, and pioneer echocardiographer, selected the case for discussion, a striking cineangiogram rather than an echocardiographic study. Ken Jue, who practised paediatric cardiology in the Central Valley of California, but attended these conferences, and had an interest in pathology, stemming from a fellowship with Jesse Edwards, was aware of the embryologic compact and spongy zones of the developing myocardium. He had seen a specimen at the department of Jesse Edwards that was pictured in different context in 2 reports. ${ }^{11,12}$ Mohrmann, then a resident in pathology, contributed the gross and histological pictures from the autopsy specimens. The noun "noncompaction" arose in a lively discussion, where the adjective "compact" had already been introduced. In their paper, they defended the new term as superior to existing ones, as it stressed the relationship of the phenomenon to its potential embryologic aetiology.

How were 8 cases collected of such a rare anomaly? Aside from the index case, over a period of 5 years Roberta Williams had remembered 2 previous cases because of their striking echoes. Two others were asymptomatic siblings the authors found in family studies. The rest came through the door of a busy service after this conference, the renaming "noncompaction," and the decision to publish.

\section{Why did it take so long?}

Although cardiologists were aware of the literature describing the embryological transition from spongy to compact myocardium, few saw the brief article in German published in 1967 and describing the contrast ventriculogram in the first report of a human case of isolated noncompaction. In my retired state, I can afford to make a prediction: that review of large past series of ventriculograms would yield several cases of noncompaction, both isolated and associated with other malformations. The findings of noncompaction had been ignored earlier because of the interest of the clinicians in the functional anatomy of the heart, that is the surgically reparable lesion. This same deflection of attention probably afflicted the anatomical pathologists of my era (see below). As cross-sectional echocardiography became feasible, and gradually provided improvements in resolution, the observation of noncompaction became easier, as far more patients were undergoing echocardiography rather than angiography. Further increasing interest were the more precise modes of assessing the myocardium, Doppler, contrast echo, computerised tomography, magnetic resonance imaging, and so on.

Finally, we come to the present day. Now there is the growing applicability of genetics, and the discovery of several genes and locuses of interest in association with human noncompaction, as well as the experimental production of alleged noncompaction in animals. A long road of development in science and technology has taken us here.

\section{Lack of recognition by pathologists: the great disparity}

The knowledge that the spongy layer of the myocardium of the early embryo disappears concomitant with the development of the compact myocardium is not new. In 1892 the Harvard embryologist, Charles Sedgwick Minot wrote: "The muscles soon arrange themselves into a spongy structure, each web of the spongework being covered by endothelium, but during the $3 \mathrm{rd}$ and 4 th month the musculature gradually becomes more compact, so that at the beginning of the 5 th month the sponge structure is confined to the innermost layers of the muscular wall." ${ }^{\prime 3}$ It was no surprise to me, therefore, that the esteemed pathologist with whom I discussed my amazing ventriculogram of 1978 responded, "Oh, spongy myocardium", and showed me 2 cases from his collection. Both specimens demonstrated 2 to $3 \mathrm{~cm}$ diameter apical areas of almost full-thickness sponge, with hardly any compact zone, yet with the same total thickness as the rest of the myocardium. Both adolescent patients had died of unrelated causes, with large dilated and hypertrophied hearts due to repeated attacks of acute rheumatic fever and valvitis. The clinically insignificant areas of spongy myocardium in these specimens resulted in the question from the 
pathologist "What of it?", but these hearts looked nothing like the spongy appearance of the myocardium that had so startled me in my own patient.

Today, there is an abundance of clinical reports of noncompaction in the medical literature. A striking example is the report from all of Australia. ${ }^{14}$ The authors noted $9.2 \%$ of echocardiograms, on patients up to 10 years old with cardiomyopathies, demonstrated noncompaction when reviewed by a single echocardiographer. In contrast, when I asked several experienced pathologists how many cases of spongy myocardium they had seen, the answer usually was "none" or "one." There is only one report in the literature from a group of pathologists initiating a review of their extensive collection to look specifically for noncompaction. ${ }^{15}$ This report was not prompted by clinicians who had previously diagnosed noncompaction, seeking pathologic confirmation. Yet there are numerous convincing pictorial examples of such confirmation by pathologists. Why is it so easy for a pathologist to confirm noncompaction, and yet so difficult to see it when not looking for it? I am going to resort to some speculation here in an attempt to understand this disparity. I have always been a friend of pathologists, and have obtained my share of autopsy permits in the era when that was expected on any academic service, so I am hoping these remarks will not offend.

- We see best when we are motivated to look for something.

- The pathologist opens the heart to see what lies inside it, and is not primarily interested in the section of myocardium he has cut through to get there. In contrast, the echocardiographer looks at the heart one section at a time, and at least one of the sectional views, optimal for seeing noncompaction, can instantly claim his interest. It is much easier to see the trabeculations in section than end on.

- A small amount of sponge, such as described above, can be easily ignored by the pathologist as probably irrelevant to the cause of death.

- The heart dies in a contracted state, which would crowd together the trabeculations, and tend to minimize the appearance of sponginess.

- If the heart dies in a state of advanced hypertrophy and dilation, it is less likely to show noncompaction as the trabeculations become stretched out and thinned, and the hypertrophy thickens the compacted fraction of the wall.

\section{Confusions and controversies}

The term "hypertrabeculation", more descriptive but less euphonious than "noncompaction," has been proposed to avoid implicating embryologic causation. Its proponents cite instances where noncompaction appeared to be acquired, a positive echocardiogram following an earlier negative one. Considering the frequency of negative echoes turning positive upon further scrutiny, this can be a shaky argument. Once recorded, an echo can be restudied, but it cannot be re-recorded. The mechanisms by which noncompaction might be acquired are listed in a review by these proponents. ${ }^{3}$ Their view of the matter has not been well received, and most writers adhere to the term noncompaction. But, suppose there really are situations where the earlier echo is equal in quality to the later ones. Does that prove that the noncompaction has been acquired? See below!

The lesion was initially said to be "isolated". While it is important that many cases of noncompaction occur as isolated anomalies, it is equally significant that noncompaction occurs in association with a wide variety of other congenital malformations. Thus far, no difference has been found between the noncompaction that is isolated and that complicating other anomalies.

A further controversy involves the relationship between so-called sinusoids and intertrabecular recesses. Some authors have explicitly denied that the spaces between trabeculations in noncompacted myocardium, lined with endocardium and bathed in ventricular blood, can be called sinusoids, which they assert are part of abnormal ventriculo-coronary connections. It is true that the earliest interest in these structures showed a confusion of what we are now calling noncompaction, and the ventriculocoronary arterial fistulous connections seen on contrast ventriculograms in the high-pressure ventricles of pulmonary atresia with intact ventricular septum. ${ }^{8}$ A simple resolution of this matter is to admit that noncompaction is itself a congenital anomaly that may be associated with other anomalies. There is no reason why cases of pulmonary atresia cannot have both ventriculo-coronary arterial fistulous connections and noncompaction of one or both ventricles. In further defence of the view that this controversy is hardly worth attention is that generations of embryologists have used the terms "sinusoids" and "intertrabecular recesses" interchangeably. For a time surgeons performed the Vineberg operation on a theory that an artery implanted into myocardium would anastomose with sinusoids. This operative approach rarely succeeded. Sinusoids in the normal mature myocardium are probably rare, if present at all. ${ }^{16}$

Still another controversy about sinusoids is an embryological matter. Do they, or do they not, in the process of compaction, become capillaries in the vascular tree of the compact myocardium? There are reports both for and against this possibility, and 
thus far the question remains unanswered. Indeed, as yet there is no certainty that the non-compacted spongy layer of the developing myocardium becomes aggregated together so as to produce the compact layer.

A further problem is the relationship to the developing coronary arteries. It is accepted that the process of compaction begins concomitant with the maturation of the coronary arterial circulation, replacing the early fetal state. This process suggests that noncompaction might be associated with defective embryology of the coronary arteries. This does sometimes occur, but in most cases of noncompaction in which the coronary arteries have been studied, they have been normal. This is consonant with the relatively new embryologic finding that the myocardial circulation first appears as a plexus of capillaries, which later develops coronary arteries and veins. Subsequently, the embryonic coronary arteries find their way to the aorta and connect to it, rather than the coronary arteries arising as buds from the aorta. ${ }^{17}$ Despite this, the sequence of development of compaction progresses from base to apex.

What, therefore, is noncompaction? The condition has no widely accepted definition. Despite the technical superiority and less observer dependency of magnetic resonance imaging, echocardiography is the usual, simplest, least expensive, and most available route to the diagnosis, and the description of the condition centres on echocardiographic findings. Most echocardiographically derived criterions specify the proportion of the full thickness of myocardium that must be noncompacted, usually expressed as the ratio of the noncompacted to the compact layers. This ratio, not yet generally agreed upon, may vary from 1 to 2.4. Whether the measurement is made at end systole or end diastole is said to be important, but disputed, and often not designated. Some authorities refuse to use a ratio, and prefer to enumerate trabeculations in a specific view. While it is known that second harmonic recording, or injection of contrast, may facilitate echocardiographic diagnosis when it is unclear, there is no requirement that either be done.

The echocardiographer scans the heart, finds the segment that is most noncompacted, judges and measures. It is thus possible to ignore the extent of involvement, since only a single segment needs to be studied. But many observers do mention extent by defining involved segments according to either a $9-{ }^{18}$ or a $17-{ }^{19}$ segment scheme, or otherwise describing distribution. To complicate further this evaluation, it has been shown in the rapidly growing infant recovering from congestive failure that the ratio may change markedly. ${ }^{20}$

As would be expected from this chaotic state of affairs, when observers have applied different sets of criterions to the same data, different groups of patients become included and excluded. A systematic study $^{21}$ comparing the application of 3 sets of criterions to patients in a dedicated clinic for cardiac failure has these results: 47 patients satisfied at least 1 set. Of that number, 17 satisfied only a single set; 37 satisfied Chin, ${ }^{10} 30$ Jenni, ${ }^{18}$ and 25 Stollberger. ${ }^{3}$ Most of the emphasis has been on the minimal requirements for the diagnosis, while remarkably little data is being reported that focuses on the important gray area between minimal diagnosis and how much noncompaction can be ignored as a normal variant. ${ }^{19,22}$ This borderline zone needs attention.

Even more disquieting in the report by Kohli and associates, ${ }^{21}$ is the extremely high prevalence. In this clinic, $24 \%$ of the patients and 5 of 60 normal controls satisfied at least one set of criterions, suggesting that the various criterions are entirely too sensitive and seem to be mining the gray area where normal noncompaction shades into the mild side of the pathologic noncompaction distribution curve. They point out that part of this problem is the ever increasing resolution afforded by new echocardiographic technology as well as the growing awareness of noncompaction, and they caution that these sources of difficulty are bound to increase.

\section{Another dimension?}

The following is speculative, but I offer it here as a means of rationalizing many observations noted in studies of ventricular noncompaction. I suggest that we should consider still another dimension - time. Time is basic to embryology. Every species has its precise normal schedule for development. The normal process of compaction is felt by embryologists to be multifactorial, as is most developmental signalling. Developmental interruption can occur at different times, as caused by different defects, and can thus lead to different manifestations. Furthermore, except for lethal situations as in some of the experimental mammalian models, the development and growth of the myocardium resume, although it is unreasonable to assume that the interval before resumption is uniform. These considerations may explain the varied and conflicting presentations of noncompaction. We see variation in intensity of involvement, particularly in the ratio of thickness of the noncompacted and compacted layers, the extent of involved segments, and a wide variety of shapes of the involved segments depending upon when, in myocardial development, the failure occurred and how long it continued.

For example, there are two vastly different, but both minimal, examples of noncompaction. Consider, on the one hand, a small but nearly full thickness area 
of sponge near the apex found incidentally at autopsy. On the other hand, consider a completely different appearance as illustrated by the 11th case in the report of Burke and colleagues ${ }^{15}$ where the noncompaction, again minimal, is generalized but requires histologic study for proof. In the former, it would seem that after most of the heart was completely compacted, development was arrested before reaching the apex and never started again, while in the latter case the arrest started early, affecting most of the ventricle but after a time, development recommenced to the point of near normalcy.

Another interesting manifestation is the so-called "undulating phenotype", ${ }^{23}$ which is the name given to the interconversion of noncompacted hearts in infancy between functionally hypertrophic and functionally dilated and vice versa. As an aside, functionally restrictive should also be included. While a facile explanation of this may be interoperator variability, it is probably a real phenomenon, and may be explained using timing, as it occurs during the early neonatal period, when the individual it is growing most rapidly. Exactly how this works is yet to be clarified.

There have been conflicting findings regarding the myocardial microcirculation in noncompaction. Some have found only the noncompacted segments to have deficient microcirculation, while in other studies the deficiency extends into compacted segments. It is clear that when trabeculations have grown to a thickness that no longer permits effective diffusion from the lumen, they must be perfused from the coronary arterial supply. In contrast to normally structured left ventricular myocardium, which is perfused in diastole by relatively straight perforating small arteries, the path to the end of a pathologic trabeculation can be long and tortuous. Add the varied configurations of noncompaction as determined by timing, and the pathologic consequences of disturbed microcirculation that cause further disturbance, namely fibrosis and thrombosis. It seems quite possible that some segments that appear to the echocardiographer to be compact may in fact be segments that were earlier spongy and have never quite normalized.

These considerations make it even more remarkable that some patients with noncompaction have survived over long periods without congestive failure. They are somewhere on these dimensional continuums where the supply equals the demand.

\section{Noncompaction as an acquired disease?}

Return for a moment to the 11th case reported by Burke and colleagues. ${ }^{15}$ The findings of noncompaction were so minimal that they required histologic confirmation, and would not have satisfied minimal echocardiographic criterions. Such pathological findings may be a better way of rationalizing "acquired hypertrabeculation" seen in rare cases of neuromuscular disease, ${ }^{24,25}$ where with gradual deterioration, already minimally noncompacted areas lose volume and pull away from each other and become visibly noncompacted to the echocardiographer. Converse thinking can be applied to other extremely rare reports interpreted as acquired or intermittent noncompaction, such as a case of chronic myocarditis associated with rickettsial infection. ${ }^{26}$ There we can postulate that the pre-existing noncompacted trabeculations were too thin to be perceived by echocardiography, but with infiltration and oedema they became larger and noticeable. As the disease subsided under treatment, the noncompaction disappeared. My career in cardiology was spent dealing with congenital disease and I admit to prejudice. I believe that all noncompaction is of embryonic origin until solidly proven otherwise.

Intimate details of the process of compaction are somewhat vague in the embryology literature. How, in noncompaction, the trabeculations in the spongy zone grow, and the zone remains spongy instead of becoming compact, as the heart grows, needs further study. The experimental embryologists soon will have tools for turning off myocardial compaction, and after a selected interval, back on. I quote from one of them: "Transgenic mouse technology is now at the point where it is possible to limit misexpression of control molecules to a given temporo-spatial point in cardiac development, thereby facilitating experiments that can examine subtle defects in cardiac development that may result in noncompaction in man." 27

\section{What of it?}

Several respected cardiologists have objected to the "fuss" about noncompaction, considering it a rare and over diagnosed condition, with a selective emphasis in the literature on the dire consequences. ${ }^{28}$ Their concern reminds me of the "innocent murmur," that nonentity that has caused real problems for patient, family, and physician. On the other hand, when noncompaction is diagnosed in the presence of congestive heart failure, arrhythmia, or thromboemolism, its clear importance makes the offer to screen asymptomatic family members good medical practice, despite the psychological risks. As better data is collected, especially in that gray area bordering on normal, polarization between believers and sceptics should weaken. But it will require prospective accumulation of longitudinal data from all age groups, and worldwide, using standardized criterions and methods. It will not be easy. The leaders in this field must come together as a working group willing 
to communicate, collaborate and compromise. This impatient nonagenarian says: "The time to begin is now." I am pleased to note that others are sensing the same urgency. ${ }^{21,29}$

\section{Acknowledgements}

I take full responsibility for the opinions and errors herewith and thank the following people who graciously responded to my queries by letter, phone, and email and those who helped in other ways to bring this to fruition:

Cardiologists: Ruben J. Acherman, Thomas K. Chin, Steven D. Colan, Perry M. Elliott, William N. Evans, Kenneth L. Jue, Alan B. Lewis, Steven E. Lipshultz, Joseph K. Perloff, Frank C. Smith, Robert E. Stanton, Jeffrey A. Towbin, Richard Van Praagh, Robert G. Weintraub, Roberta G. Williams.

Pathologists: Allen P. Burke, Jesse E. Edwards, Jeffrey D. Hubbard, Ronald Jaffe, William C. Roberts, Glenn P. Taylor, Jack L. Titus, Philip C. Ursell.

Morphologist: Robert H. Anderson.

Embryologist: David Sedmara.

North American Pediatric Cardiomyopathy Registry: Lynn A. Sleeper.

Schaffer Library of Albany Medical College: Ann Marie l'Hommedieu.

\section{References}

1. Freedom RM, Yoo S-J, Perrin D, Taylor G, Petersen S, Anderson RH. The morphological spectrum of ventricular noncompaction. Cardiol Young 2005; 15: 345-364.

2. Weiford BC, Subbarao VD, Mulhern KM. Noncompaction of the ventricular myocardium. Circulation 2004; 109: 2965-2971.

3. Stollberger C, Finsterer J. Left ventricular hypertrabeculation/ noncompaction. J Am Soc Echocardiog 2004; 17: 91-100.

4. Lurie PR. Abnormalities and diseases of the coronary vessels. In: Moss AJ, Adams FH (eds). Heart Disease in Infants, Children and Adolescents. Williams and Wilkins Co., Baltimore, 1968, pp 738-759.

5. Armer RM, Shumacker HB Jr, Lurie PR, Fisch C. Origin of the left coronary artery from the pulmonary artery without collateral circulation. Report of a case with a suggested surgical correction. Pediatrics 1963; 32: 588-593.

6. Neustein HB, Lurie PR. Endomyocardial biopsy in children: applications. In: Fenoglio JJ Jr (ed.). Endomyocardial Biopsy: Techniques and Applications. CRC Press, Boca Raton, FL, 1982, pp 125-154.

7. Bender F. Persistenz myokardialer Venensinusoide als isolierte kongenitale Fehlbildung bei einer Erwachsenen. Zeitshrift fur Kreislaufforschung 1966; 56: 58-63.

8. Dusek J, Ostadal B, Duskova M. Postnatal persistence of spongy myocardium with embryonic blood supply. Arch Pathol 1975; 99: 312-317.
9. Westwood M, Harris R, Burn JL, Barson AJ. Heredity in primary endocardial fibroelastosis. Brit Heart J 1975; 37: 1077-1084.

10. Chin TK, Perloff JK, Williams RG, Jue K, Mohrmann R. Isolated noncompaction of left ventricular myocardium. Circulation 1990; 82: 507-513.

11. VanPraagh R, Ongley PA, Swan HJ. Anatomic types of single or common ventricle in man. Morphologic and geometric aspects of 60 necropsied cases. Am J Cardiol 1964; 13: 367-386.

12. Feldt RH, Rahimtoola SH, Davis GD, Swan HJC, Titus JL. Anomalous ventricular myocardial patterns in a child with complex congenital heart disease. Am J Cardiol 1969; 23: 732-734.

13. Minot CS. Human Embryology. William Wood \& Co., New York, 1892, pp 478-479.

14. Nugent AW, Daubeney PEF, Chondros P, et al. The epidemiology of childhood cardiomyopathy in Australia. N Eng J Med 2003; 348: 1639-1646.

15. Burke A, Mont E, Kutys R, Virmani R. Left ventricular noncompaction: a pathological study of 14 cases. Hum Pathol 2005; 36: 403-411.

16. Tsang JC-C, Chiu RC-J. The phantom of "myocardial sinusoids": a historical reappraisal. Ann Thorac Surg 1995; 60: 1831-1835.

17. Vrancken Peeters M-PFM, Gittenberger-De Groot AC, Mentink MMT, Hungerford JE, Little CD, Poelmann RE. The development of the coronary vessels and their differentiation into arteries and veins in the embryonic quail heart. Dev Dyn 1997; 208: 338-348.

18. Jenni R, Oechslin EN, van der Loo B. Isolated ventricular noncompaction of the myocardium in adults. Heart 2007; 93: 11-15.

19. Petersen SE, Selvanayagam JB, Wiesmann F, et al. Left ventricular non-compaction. Insights from cardiovascular magnetic resonance imaging. J Am Coll Cardiol 2005; 46: 101-105.

20. Toyono M, Kondo C, Nakajima Y, Nakazawa M, Momma K, Kusakabe K. Effects of carvedilol on left ventricular function, mass, and scintigraphic findings in isolated left ventricular compaction. Heart 2001; 86: e4-e6.

21. Kohli SK, Pantazis AA, Shah JS, et al. Diagnosis of left ventricular non-compaction in patients with left ventricular systolic dysfunction: time for a reappraisal of diagnostic criteria? Eur Heart J 2008; 29: 89-95.

22. Donthireddi U, Najovits AJ, Belanger AR, Goldman ME. Isolated left ventricular noncompaction: a normal 2-D echocardiographic variant? J Am Soc Echocardiogr 2006; 19: 635.

23. Pignatelli RH, McMahon CJ, Dreyer WJ, et al. Clinical characterization of left ventricular noncompaction in children. A relatively common form of cardiomyopathy. Circulation 2003; 108: $2672-2678$.

24. Finsterer J, Stollberger C. Spontaneous left ventricular hypertrabeculatiion in dystrophin duplication based Becker's muscular dystrophy. Herz 2001; 26: 477-481.

25. Finsterer J, Stollberger C, Gaismayer K, Janssen B. Acquired noncompaction in Duchenne muscular dystrophy. Int J Cardiol 2006; 106: 420-421.

26. Pfammatter JP, Paul T, Flik J, Drescher J, Kalifelz HC. Q-Fieberassoziierte Myokarditis bei einem 14 jahrigen Jungen. Zeitschrift fur Kardiol 1995; 84: 947-950.

27. Breckenridge RA, Anderson RH, Elliott PM. Isolated left ventricular non-compaction: the case for abnormal myocardial development. Cardiol Young 2007; 17: 124-129.

28. Ovadia M, Duque KS. Sporadic isolated left ventricular noncompaction: dread disease or not? PACE 2007; 30: 455-457.

29. Anderson RH. Ventricular non-compaction a frequently ignored finding? Editorial. Eur Heart J 2008; 29: 10-11. 